\title{
Safety of lumbar puncture in comatose children with clinical features of cerebral malaria
}

\section{OPEN}

Christopher A. Moxon, MRCPCH, PhD

Lei Zhao, MS

Chenxi Li, PhD

Karl B. Seydel, MD, PhD

Ian J. MacCormick, MBChB, PhD

Peter J. Diggle, PhD

Macpherson Mallewa, MRCPCH, PhD

Tom Solomon, FRCP, $\mathrm{PhD}$

Nicholas A. Beare, FRCOphth, MD

Simon J. Glover, FRCOphth

Simon P. Harding, FRCOphth, MD Susan Lewallen, MD Sam Kampondeni, MD Michael J. Potchen, MD Terrie E. Taylor, DO

Douglas G. Postels, MD, MS

Correspondence to

Dr. Postels:

douglas.postels@ht.msu.edu

Supplemental data at Neurology.org

\section{ABSTRACT}

Objective: We assessed the independent association of lumbar puncture (LP) and death in Malawian children admitted to the hospital with the clinical features of cerebral malaria (CM).

Methods: This was a retrospective cohort study in Malawian children with clinical features of CM. Allocation to LP was nonrandom and was associated with severity of illness. Propensity scorebased analyses were used to adjust for this bias and assess the independent association between LP and mortality.

Results: Data were available for 1,075 children: 866 (80.6\%) underwent LP and 209 (19.4\%) did not. Unadjusted mortality rates were lower in children who underwent LP (15.3\% vs $26.7 \%$ in the no-LP group) but differences in covariates between the 2 groups suggested bias in LP allocation. After propensity score matching, all covariates were balanced. Propensity score-based analyses showed no change in mortality rate associated with LP: by inverse probability weighting, the average risk reduction was $2.0 \%$ at 12 hours (95\% confidence interval $-1.5 \%$ to $5.5 \%, p=$ 0.27 ) and $1.7 \%$ during hospital admission ( $95 \%$ confidence interval $-4.5 \%$ to $7.9 \%, p=0.60$ ). Undergoing LP did not change the risk of mortality in subanalyses of children with severe brain swelling on MRI or in those with papilledema.

Conclusion: In comatose children with suspected CM who were clinically stable, we found no evidence that LP increases mortality, even in children with objective signs of raised intracranial pressure. Neurology ${ }^{\circledR}$ 2016;87:2355-2362

\section{GLOSSARY}

$\mathbf{C I}=$ confidence interval; $\mathbf{C M}=$ cerebral malaria; $\mathbf{I C P}=$ intracranial pressure; $\mathbf{L P}=$ lumbar puncture.

Cerebral malaria (CM) — defined as coma, Plasmodium falciparum parasitemia, and the exclusion of other causes of encephalopathy-is a leading cause of death in sub-Saharan Africa. ${ }^{1,2}$ CNS coinfections are well recognized in these patients, ${ }^{3}$ and can only be reliably excluded by lumbar puncture (LP).

Despite its diagnostic utility, performing LPs in children with suspected CM is controversial because the disease may cause raised intracranial pressure (ICP). ${ }^{2}$ Brain swelling has recently been shown to be an independent predictor of death in CM. ${ }^{4}$ Some physicians are concerned that LP in the context of diffusely increased ICP may precipitate fatal herniation ${ }^{2,5,6}$; others believe the procedure is safe in the absence of overt brain shift. ${ }^{7,8}$

Executing a randomized clinical trial to determine if LP is associated with death in children with CM would be problematic. Instead, we carried out a retrospective analysis of children with

\footnotetext{
From the Institute of Infection and Global Health (C.A.M., T.S.) and Department of Eye and Vision Science, Institute of Ageing and Chronic Disease (I.J.M., N.A.B., S.P.G., S.P.H.), University of Liverpool (S.P.H.), UK; Departments of Epidemiology and Biostatistics (L.Z., C.L.) and Osteopathic Medical Specialties (K.B.S.) and International Neurology and Psychiatry Epidemiology Program (D.G.P.), Michigan State University, East Lansing; Lancaster University (P.J.D.), UK; Department of Paediatrics and Child Health (M.M.) and the Blantyre Malaria Project (T.E.T.), University of Malawi College of Medicine, Blantyre; St. Paul's Eye Unit (N.A.B.), Royal Liverpool University Hospital; School of Medicine (S.J.G.), University of St. Andrews, UK; Kilimanjaro Centre for Community Ophthalmology (KCCO) (S.L.), University of Cape Town, Department of Ophthalmology, OMB Groote Schuur Hospital Observatory, South Africa; Department of Radiology (S.K.), Queen Elizabeth Central Hospital, Blantyre, Malawi; and Department of Imaging Services (M.J.P.), University of Rochester, NY.

Go to Neurology.org for full disclosures. Funding information and disclosures deemed relevant by the authors, if any, are provided at the end of the article. The Article Processing Charge was paid by the Wellcome Trust.

This is an open access article distributed under the terms of the Creative Commons Attribution License 4.0 (CC BY), which permits unrestricted use, distribution, and reproduction in any medium, provided the original work is properly cited.
} 
clinical features of CM in whom LPs were performed unless there were asymmetrical neurologic findings or the admitting clinician believed the child was medically unstable.

To adjust for the selection bias against children who were more severely ill and thus had a higher chance of a fatal outcome, we used propensity score-based analyses. ${ }^{9}$ The propensity score represents the probability, based on observed clinical characteristics, that a participant received the intervention-in this case, an LP. Matching children by propensity score controls for illness severity, in effect simulating a clinical trial. We used this approach to assess the association between LP and death within 12 hours of admission and during the entire hospitalization.

METHODS We studied comatose (Blantyre Coma Score $\leq 2$ ) children aged 6 months to 16 years, admitted to a study investigating CM pathogenesis on the Pediatric Research Ward, Queen Elizabeth Central Hospital, Blantyre, Malawi, from January 1997 to June 2013.

Children with neck stiffness had an LP performed prior to research ward admission. Those with visibly cloudy CSF were enrolled in studies on meningitis treatment, were not enrolled in the parent study, and are not included here. Children discovered to have meningitis after research ward admission were included.

LPs were performed using 21-gauge needles in children deemed medically stable by the admitting clinician, following informed parental consent. LPs were performed either before research ward admission (in the emergency department or general pediatric ward) or on the research ward within 30 minutes of admission. Twelvehour mortality was determined from the time of LP (in those who underwent LP) or from the time of research ward admission (in those who did not undergo LP). Children had a funduscopic examination by the admitting clinician and if papilledema was suspected, an LP was not performed. Following admission investigations, including LP, definitive funduscopic examination was performed by an ophthalmologist; the ophthalmologist's determination of the presence or absence of papilledema was used in our analyses. LPs were done in children with papilledema when it was recognized by the ophthalmologist after LP performance. ${ }^{10}$ The ophthalmologist's funduscopic examination also assessed for characteristic retinal changes that are a sensitive and specific indicator of the presence of sequestered malaria-infected erythrocytes in the brain. ${ }^{11}$ This assessment distinguishes children with retinopathypositive $\mathrm{CM}$ from those with retinopathy-negative $\mathrm{CM}$, who are more likely to have a nonmalarial cause of coma. ${ }^{11}$

Parasitemic patients were treated with IV quinine. Adjunctive ceftriaxone was given until clinical recovery to all children in whom an LP was omitted. Among children who received an LP, aparasitemic children and children with retinopathy-negative $\mathrm{CM}$ were given empirical ceftriaxone pending blood cultures, whereas children with retinopathy-positive CM were only given ceftriaxone if there was significant CSF pleocytosis (leukocytes $>30 / \mu \mathrm{L}$ ), signs of sepsis, or fever following parasite clearance.

Beginning in 2009, after LP, children who were clinically stable underwent brain MRI with a $0.35 \mathrm{~T}$ Signa Ovation Excite scanner (GE Healthcare, Milwaukee, WI) within 12 hours of admission. MRI scans were independently interpreted by 2 radiologists. ${ }^{12}$

Study protocol approvals, registrations, and patient consents. The parent study's protocol was approved by the University of Malawi College of Medicine Research Ethics Committee and the Biomedical Institutional Review Board of Michigan State University.

Statistical analysis. Propensity score calculations included characteristics likely to influence a clinician's decision to perform an LP and those previously established as being associated with fatal outcome, including the following:
1. Depth of coma (Blantyre Coma Score)
2. Systolic blood pressure for age
3. Weight-for-height $z$ score (nutritional status)
4. Respiratory distress or acidotic breathing
5. Pulse rate
6. Cardiovascular system examination (signs of heart failure)
7. Sex
8. Admission blood glucose concentration
9. Peripheral parasite density
10. Hematocrit
11. Malarial retinopathy status
12. Papilledema

The various propensity score-based analysis methods each have strengths and weaknesses. To ensure methodologic rigor, we used 3 methods to assess the independent association of LP with mortality: (1) inverse probability weighting, (2) unconditional logistic regression where propensity score was an independent variable, and (3) nearest neighbor propensity score matching (with replacement). ${ }^{13}$ We imputed retinopathy status in 456 participants in whom this variable was missing using logistic regression based on predictive characteristics: platelet count, hematocrit, and glucose. ${ }^{14}$ In participants where the calculated likelihood of being retinopathy-positive was greater than $50 \%$, participants were imputed to be retinopathy-positive; if not, they were imputed as being retinopathy-negative. Papilledema was considered an important covariate for the calculation of propensity score but its determination by an ophthalmologist (considered the gold standard) was missing in a significant number of children. We therefore performed analyses both with papilledema (to account for the variable) and without it (to maximize study power) included in the calculation of propensity score. Other missing data were handled by listwise deletion. In all analyses, a $p$ value $<0.05$ was considered statistically significant. A detailed description of the statistical methods used in our analyses may be found in appendix e-1 at Neurology.org.

\section{RESULTS Characteristics of the patients and balance} before and after propensity score matching. A total of 2,278 comatose patients were admitted to the research ward between January 1997 and June 2013. Of these, 451 children were excluded: 442 had missing data on one or more covariates used in the calculation of propensity score (after retinopathy status imputation); 9 had missing data on LP performance (figure 1). Mortality rates in participants included in our analyses were not different, compared to those excluded due to missing covariates $(p=0.34$ for 12 -hour mortality and 0.50 for mortality during hospitalization). In the analysis omitting papilledema 


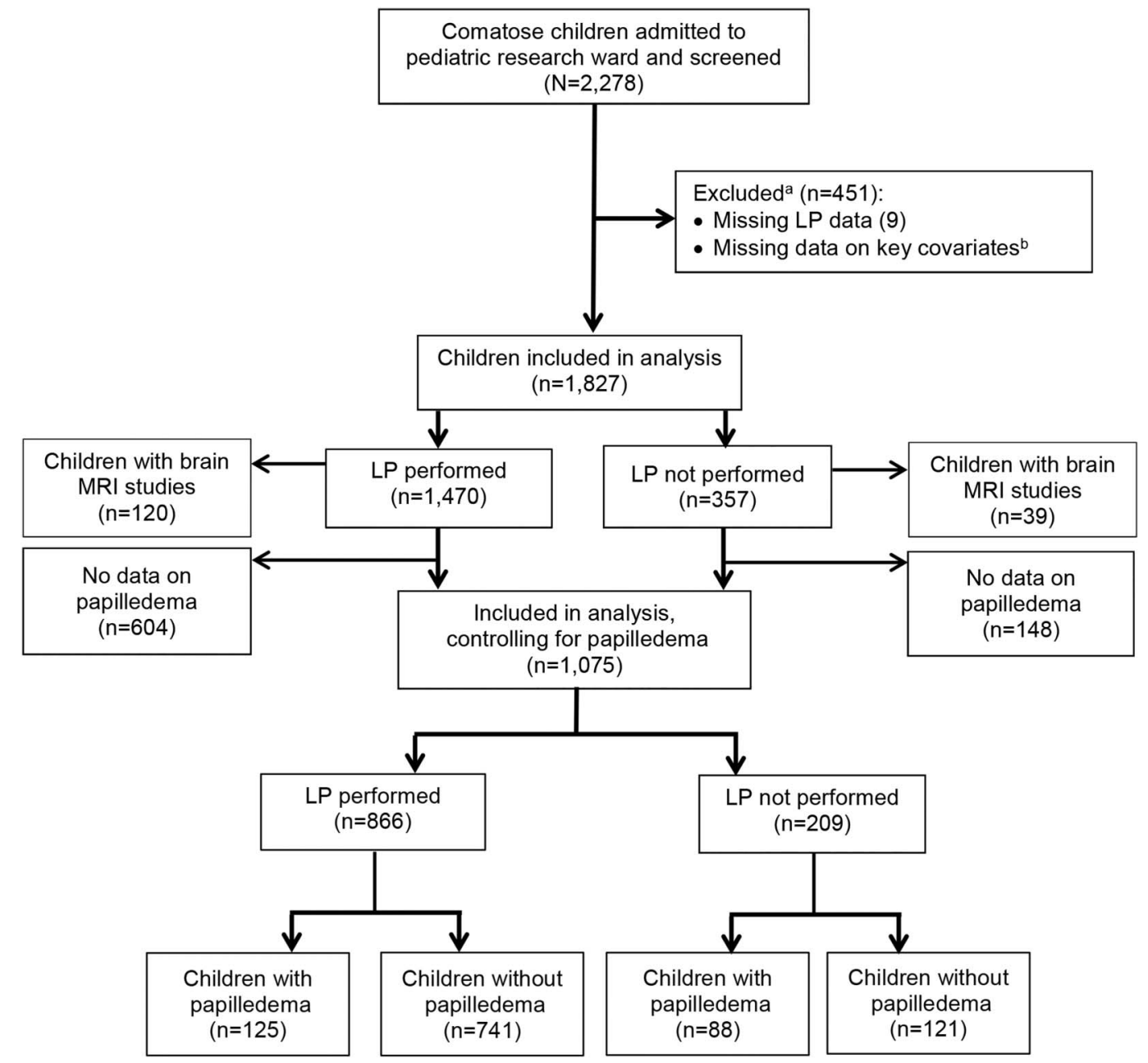

a Compared to those included, the 451 children excluded from analysis did not differ by sex, age, or mortality rate (using a threshold of a $10 \%$ difference as clinically meaningful). ${ }^{b}$ Covariates missing (number of children and covariate): 37 malarial retinopathy, 214 respiratory distress, 67 peripheral parasite density, 27 hematocrit, 90 blood pressure, 27 heart examination, 11 pulse, 10 glucose, 4 sex, 5 age (252 children have missing malarial retinopathy in original data, among which retinopathy status of 215 children are imputed from a logistic regression with hematocrit, platelet count, glucose as covariates: retinopathy status imputed as positive if predicted probability $>0.5)$. $\mathrm{LP}=$ lumbar puncture.

from the calculation of propensity score, 1,827 patients were included: $1,470(80.5 \%)$ of these patients received an LP and 357 (19.5\%) did not. In the analysis that included papilledema, 1,075 patients were included, of whom 866 (80.6\%) had an LP and 209 (19.4\%) did not. Propensity scores of children who did and did not undergo LP overlapped significantly, indicating that propensity score matching analyses were feasible (figure 2). Fortyone of the 866 children who underwent LP (4.7\%) had CSF pleocytosis (leukocytes $>10$ ); a bacterial pathogen was isolated from CSF in 20 cases and tuberculous meningitis was diagnosed in 3 patients. A total of $87.6 \%$ (942 of 1,075 children) had malaria parasitemia; of these, $67.9 \%$ were malarial retinopathy-positive.

Before propensity score matching, a number of baseline characteristics were not balanced between children who did and did not undergo LP, as indicated by standardized differences greater than 0.1 $(10 \%)$ in these variables ${ }^{15}$ (tables 1 and 2 ). In the analysis in which papilledema was included in the calculation of propensity score, the 1,075 matched pairs generated had acceptable balance for all baseline characteristics (table 1). When papilledema was excluded from the calculation of propensity score, the 1,827 matched pairs were balanced for all baseline characteristics except papilledema, which in those children with data on this covariate was more than twice as frequent in children who did not receive an LP than in those who did (38\% vs 16\%; standardized difference 53\%; table 2).

Since the presence of papilledema influenced whether or not a child received an LP, we report our findings from the analyses where papilledema was included in propensity score calculation. Results 
Figure 2 Distribution of propensity scores in those who did not (A) and did (B) receive lumbar punctures

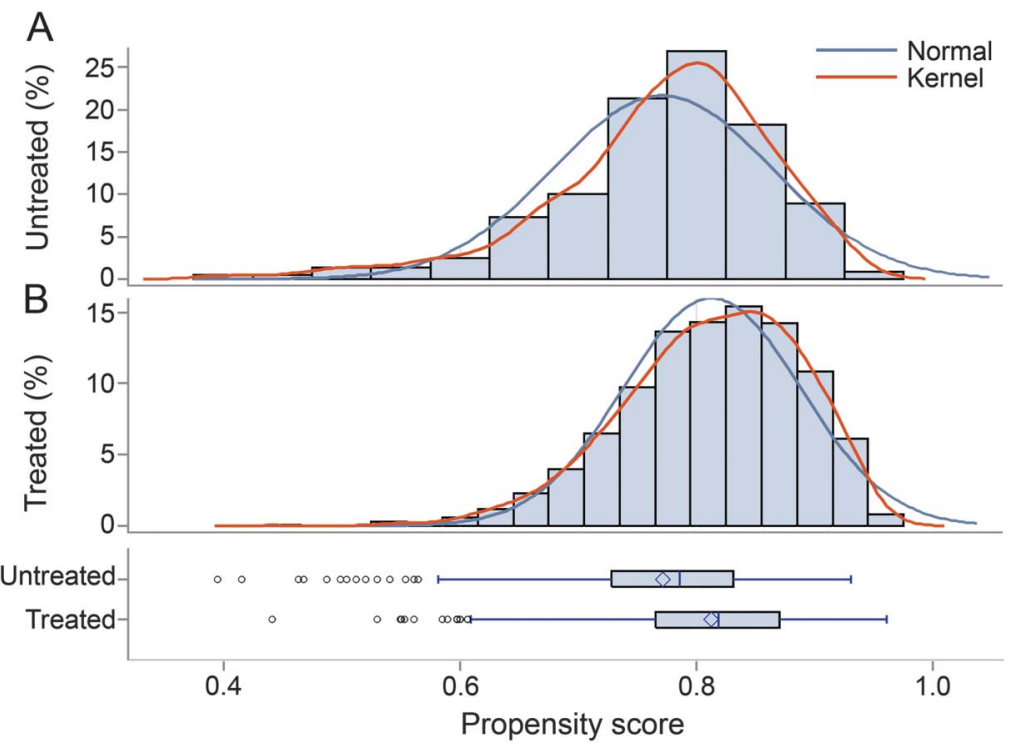

Overlap of curves demonstrates that propensity score matching analyses are feasible.

of the analyses where papilledema was not used in propensity score calculation are presented in table e-1. We performed separate analyses for patients suspected to have CM on presentation (Table 3), as well as those who strictly fulfilled WHO clinical criteria (coma malaria parasitemia, no other coma etiology evident [table e-2]), and both showed similar results.

The proportion of children who were HIVpositive was balanced in the LP vs no LP groups after propensity score matching: $12.2 \%$ vs $9.6 \%$ (standardized difference 0.08 ) in the analysis including papilledema in propensity score calculation and $13.1 \%$ vs $12.5 \%$ (standardized difference 0.02 ) in the analysis excluding papilledema.

Association of LP with mortality at $\mathbf{1 2}$ hours. Unadjusted 12-hour mortality was $7.9 \%$ lower in children who received an LP compared to those who did not (95\% confidence interval [CI] 5.2\%$10.7 \%, p<0.0001$; table 3$)$. In the propensity score-adjusted analysis, 12-hour mortality was not significantly different in children who underwent LP compared to those who did not (table 3). This was the case regardless of the propensity score-based analysis method used. The effect size was similar and insignificant in all 3 statistical methods.

Association of LP with mortality during hospitalization. Unadjusted overall mortality was $11.4 \%$ lower in the children who received LPs compared to those who did not (95\% CI 7.4\%-15.4\%, $p<0.0001$;

Table 1 Baseline characteristics of the children before and after propensity score matching (analysis including papilledema in the calculation of propensity score)

\begin{tabular}{|c|c|c|c|c|c|c|c|c|c|c|}
\hline & \multicolumn{5}{|c|}{ Before propensity score matching } & \multicolumn{5}{|c|}{$\begin{array}{l}\text { After propensity score matching ( } 1,075 \text { matched pairs of } \\
\text { LP and non-LP participants) }\end{array}$} \\
\hline & \multicolumn{2}{|l|}{$\begin{array}{l}\text { No LP } \\
\text { (n= 209) }\end{array}$} & \multicolumn{2}{|l|}{$\begin{array}{l}\text { LP done } \\
(n=866)\end{array}$} & \multirow[b]{2}{*}{$\begin{array}{l}\text { Standardized } \\
\text { difference }\end{array}$} & \multicolumn{2}{|l|}{ No LP } & \multicolumn{2}{|l|}{ LP done } & \multirow[b]{2}{*}{$\begin{array}{l}\text { Standardized } \\
\text { difference }\end{array}$} \\
\hline & Mean & SD & Mean & SD & & Mean & SD & Mean & SD & \\
\hline Date of admission, mo & Jan 2005 & NA & Jan 2004 & NA & $0.30^{a}$ & Apr 2004 & NA & Dec 2003 & NA & 0.04 \\
\hline Blantyre Coma Score & 1.29 & 0.73 & 1.31 & 0.71 & 0.08 & 1.44 & 0.71 & 1.39 & 0.71 & 0.07 \\
\hline Papilledema present, proportion & 0.42 & 0.49 & 0.14 & 0.35 & $0.65^{a}$ & 0.18 & 0.38 & 0.21 & 0.41 & 0.08 \\
\hline Acidotic breathing present, proportion & 0.41 & 0.49 & 0.35 & 0.48 & $0.14^{a}$ & 0.40 & 0.49 & 0.36 & 0.48 & 0.10 \\
\hline Respiratory rate, breaths/min & 48.6 & 13.9 & 46.1 & 12.9 & $0.19^{a}$ & 46.9 & 14.0 & 45.9 & 12.7 & 0.08 \\
\hline $\begin{array}{l}\text { Systolic blood pressure within normal } \\
\text { range for age }{ }^{\mathrm{a}}\end{array}$ & 1.01 & 0.27 & 1.01 & 0.19 & 0.00 & 1.00 & 0.24 & 1.01 & 0.18 & 0.06 \\
\hline Weight-for-height z score & -1.12 & 1.34 & -1.06 & 1.41 & 0.04 & -0.99 & 1.32 & -1.04 & 1.42 & 0.04 \\
\hline Admission glucose, $\mathrm{mmol} / \mathrm{L}$ & 6.10 & 3.17 & 6.83 & 4.00 & $0.20^{a}$ & 5.98 & 2.77 & 6.20 & 3.93 & 0.06 \\
\hline Hematocrit, \% & 22.2 & 8.24 & 22.6 & 8.19 & $0.16^{\mathrm{a}}$ & 23.6 & 7.94 & 23.4 & 8.19 & 0.03 \\
\hline Retinopathy present, proportion & 0.74 & 0.44 & 0.60 & 0.49 & $0.21^{a}$ & 0.64 & 0.48 & 0.62 & 0.49 & 0.03 \\
\hline Parasite count per $\mu \mathrm{L}$, logarithm & 10.3 & 3.41 & 9.02 & 4.40 & $0.32^{\mathrm{a}}$ & 9.39 & 3.96 & 9.19 & 4.27 & 0.05 \\
\hline
\end{tabular}

Abbreviations: CVS = cardiovascular system; LP = lumbar puncture.

${ }^{a}$ Characteristics where the standardized difference is greater than $0.1(10 \%)$.

${ }^{\mathrm{b}} \mathrm{O}=$ Below reference range, $1=$ within reference range, 2 = above reference range. 
Table 2 Baseline characteristics of the children before and after propensity score matching (analysis excluding papilledema in the calculation of propensity score)

\begin{tabular}{|c|c|c|c|c|c|c|c|c|c|c|}
\hline & \multicolumn{5}{|c|}{ Before propensity score matching } & \multicolumn{5}{|c|}{$\begin{array}{l}\text { After propensity score matching ( } 1,827 \text { matched pairs } \\
\text { of } L P \text { and non-LP participants) }\end{array}$} \\
\hline & \multicolumn{2}{|l|}{$\begin{array}{l}\text { No LP } \\
(n=357)\end{array}$} & \multicolumn{2}{|c|}{$\begin{array}{l}\text { LP done } \\
(\mathrm{n}=1,470)\end{array}$} & \multirow{2}{*}{$\begin{array}{l}\text { Standardized } \\
\text { difference }\end{array}$} & \multicolumn{2}{|l|}{ No LP } & \multicolumn{2}{|l|}{ LP done } & \multirow{2}{*}{$\begin{array}{l}\text { Standardizec } \\
\text { difference }\end{array}$} \\
\hline & Mean & SD & Mean & SD & & Mean & SD & Mean & SD & \\
\hline Date of admission, mo & Nov 2003 & NA & Feb 2003 & NA & 0.08 & Nov 2003 & NA & Feb 2003 & NA & 0.08 \\
\hline Blantyre Coma Score & 1.21 & 0.75 & 1.31 & 0.71 & $0.13^{a}$ & 1.31 & 0.72 & 1.29 & 0.72 & 0.02 \\
\hline Papilledema present, proportion & 0.42 & 0.49 & 0.14 & 0.35 & $0.65^{a}$ & 0.38 & 0.49 & 0.16 & 0.36 & $0.53^{a}$ \\
\hline Acidotic breathing, proportion present & 0.47 & 0.50 & 0.36 & 0.48 & $0.21^{\mathrm{a}}$ & 0.37 & 0.48 & 0.38 & 0.49 & 0.02 \\
\hline Respiratory rate, breaths/min & 48.9 & 14.7 & 46.1 & 13.1 & $0.20^{a}$ & 47.4 & 13.8 & 46.2 & 13.1 & 0.09 \\
\hline Weight-for-height z score & -1.01 & 1.33 & -1.03 & 1.41 & 0.02 & -0.92 & 1.29 & -1.05 & 1.41 & 0.09 \\
\hline Admission glucose, $\mathrm{mmol} / \mathrm{L}$ & 6.14 & 3.89 & 6.72 & 3.96 & $0.15^{\mathrm{a}}$ & 6.76 & 4.17 & 6.64 & 3.87 & 0.03 \\
\hline Hematocrit, \% & 22.3 & 8.32 & 23.8 & 8.08 & $0.19^{a}$ & 23.8 & 8.41 & 23.4 & 8.12 & 0.05 \\
\hline Retinopathy present, proportion & 0.75 & 0.43 & 0.60 & 0.49 & $0.33^{a}$ & 0.63 & 0.48 & 0.63 & 0.48 & 0.01 \\
\hline Parasite count per $\mu \mathrm{L}$, logarithm & 10.2 & 3.26 & 9.21 & 4.26 & $0.27^{a}$ & 9.91 & 3.40 & 9.84 & 4.12 & 0.02 \\
\hline
\end{tabular}

Abbreviations: CVS = cardiovascular system; LP = lumbar puncture.

${ }^{a}$ Characteristics where the standardized difference is greater than $0.1(10 \%)$.

${ }^{\mathrm{b}} \mathrm{O}=$ Below reference range, $1=$ within reference range, $2=$ above reference range.

table 3). After adjustment for propensity score, children who did and did not receive LPs had similar mortality rates (table 3). The effect size was similar in all 3 statistical methods. For children with WHO clinically defined CM, there was no significant difference in adjusted overall mortality rates for those who underwent LP, compared to those who did not (table e-2).

Influence of papilledema on mortality after LP. To determine whether the presence of papilledema changed the association of LP with mortality, we assessed interactions between papilledema and LP in our inverse probability-weighted regression analyses. In the model where outcome was mortality at 12 hours, the effect of LP on mortality was not different when comparing children with or without papilledema (difference in treatment effect 5.9\%, 95\% CI $-1.4 \%$ to $13.2 \%, p=0.12$ ). Similar results were obtained for overall mortality (difference in treatment effect $8.8 \%, 95 \% \mathrm{CI}-2.5 \%$ to $20.2 \%, p=0.13$ ), indicating no effect modification by papilledema.

Association of LP with mortality in children with severely increased brain volume on MRI. A total of 166 children underwent brain MRI scans after LP performance.
Three children died within 12 hours of admission: 1 had an LP and the other 2 did not. Overall mortality of children who underwent MRI was $12.7 \%$ $(n=21)$.

When restricting our subanalysis to the 101 children who had severe brain swelling with loss of brain sulci and cisterns, with or without evidence of herniation, mortality during hospitalization was $17.1 \%$ lower in the children who received an LP compared to those who did not $(95 \% \mathrm{CI}-1.4 \%$ to $35.6 \%$, $p=0.07$, inverse probability weighting). Mortality within 12 hours was lower in children who underwent LP by $6.3 \%$ (95\% CI $-1.9 \%$ to $14.5 \%, p=$ $0.13)$. To maximize the power of this subanalysis, we did not use papilledema in the calculation of propensity score.

DISCUSSION In this large single-center study of comatose African children without overt meningismus but with suspected $\mathrm{CM}$, we found no evidence that those undergoing LP were at increased risk of death. This was true even in a subanalysis of children with MRI evidence of severe brain swelling, several of whom had early evidence of herniation. While both papilledema and 


\begin{tabular}{|c|c|c|c|c|c|c|}
\hline \multirow[t]{2}{*}{ Table 3} & \multicolumn{6}{|c|}{$\begin{array}{l}\text { Comparison of mortality rates before and after propensity score matching when papilledema was } \\
\text { used in the calculation of propensity score }\end{array}$} \\
\hline & & No LP & LP & $\begin{array}{l}\text { Treatment } \\
\text { effect }^{\mathrm{a}}\end{array}$ & $95 \% \mathrm{Cl}$ & p Value \\
\hline \multicolumn{7}{|c|}{ Before adjusting for confounding variables } \\
\hline No. & & 431 & $1,838^{b}$ & & & \\
\hline 12-Hou & ortality, n (\%) & $59(13.7)$ & $107(5.8)$ & 7.9 & 5.2 to 10.7 & $<0.0001$ \\
\hline Mortalit & luring hospitalization, $n$ (\%) & $115(26.7)$ & 281 (15.3) & 11.4 & 7.4 to 15.4 & $<0.0001$ \\
\hline \multicolumn{7}{|c|}{ After adjusting for confounding variables } \\
\hline No. & & 209 & 866 & & & \\
\hline Inverse & obability weighting, \% & 7.1 & 5.1 & 2.0 & -1.5 to 5.5 & 0.268 \\
\hline Logistic & gression, \% ${ }^{c}$ & 7.9 & 5.3 & 2.6 & -0.8 to 6.0 & 0.132 \\
\hline Matchin & & 7.1 & 5.0 & 2.1 & -2.1 to 6.2 & 0.329 \\
\hline \multicolumn{7}{|c|}{ Mortality during hospitalization } \\
\hline Inverse & obability weighting, \% & 16.8 & 15.1 & 1.7 & -4.5 to 7.9 & 0.595 \\
\hline Logistic & gression, $\%^{c}$ & 16.9 & 15.3 & 1.6 & -4.0 to 7.3 & 0.572 \\
\hline Matchin & & 16.9 & 15.2 & 1.7 & -5.0 to 8.4 & 0.625 \\
\hline
\end{tabular}

Abbreviations: $\mathrm{Cl}=$ confidence interval; $\mathrm{LP}=$ lumbar puncture.

a Percentage reduction in mortality in those who underwent LP compared to those who did not.

${ }^{b}$ Eight participants had missing values on 12-hour outcome because we could not confirm the exact time that LP was performed. These participants were included in the mortality during hospitalization analysis.

${ }^{\mathrm{c}}$ The point estimate for treatment effect was determined by logistic regression and the corresponding $\mathrm{Cl}$ was obtained by bootstrap.

brain swelling on MRI are independently associated with fatal outcome in $\mathrm{CM}^{4,16}$ in children lacking lateralizing signs and judged to be stable enough to tolerate LP by the admitting clinician, undergoing LP did not change mortality risk in patients with these abnormalities.

The independent association of LP and death in $\mathrm{CM}$ or other CNS infections that diffusely raise ICP has not been studied. ${ }^{7}$ Case series of patients with meningitis ${ }^{5}$ and $\mathrm{CM}^{17}$ have described temporal associations between LP and death, but fatal herniation in the absence of LP is recognized in both conditions. ${ }^{5,7}$ Since these case series included few patients with diffuse brain swelling who did not undergo LP, they were unable to assess the independent association between LP and outcome. By contrast, our cohort included large groups of children with diffuse brain swelling who did and did not undergo LP, allowing us to test the independent effect of LP on outcome using propensity-score matching. Mortality rates were high in both those who underwent $\mathrm{LP}$ and those who did not. We found no evidence that undergoing LP independently increased the risk of death.

These findings are in keeping with experiments investigating CSF dynamics in human cadavers where rapid equilibration between intraspinal and intracranial compartments was seen when LP was performed. ${ }^{17}$ Failure of equilibration and herniation occurred only when free CSF movement was obstructed. We surmise that LP does not exacerbate herniation in CM because, during LP, the CSF pressure is able to rapidly equilibrate. It is important to note that this may not be the case in patients with raised ICP of different etiologies (e.g., spaceoccupying lesion), which may impair the free movement of CSF.

$\mathrm{CM}$ is the most common cause of encephalopathy in sub-Saharan Africa and is therefore a differential diagnosis in a high proportion of children with suspected brain infection. If clinicians are concerned that LP is not safe in this clinical scenario, LPs are likely to be omitted. Omission of LPs leads to empirical antimalarial and antibiotic administration with suboptimal management through both undertreatment and overtreatment. Frequently, children with suspected CM recover within 24 hours of initiating treatment. If both antibiotics and antimalarials are given and an LP has not been performed, the underlying etiology (meningitis, CM, or both) is difficult to determine. Performing an LP after recovery of consciousness and partial treatment is suboptimal because in malariaendemic settings, molecular diagnostics are rarely available. If an LP is not done at admission, one clinical option is to provide the full course of antibiotic and antimalarial treatment to all children, resulting in many children receiving unnecessary IV drugs, experiencing longer hospital stays, and placing strain on highly limited resources. Alternatively, clinicians could stop medications and discharge the patient, risking incomplete treatment. Epidemiologically, omitting LPs obscures 
recognition of changes in prevalence of relevant pathogens. On a population level, the cumulative effects of these suboptimal situations are substantial.

Though retrospective, our study has several strengths. We included data collected over 16 years, achieving a sample size that would have been difficult to accrue in a prospective trial. We included funduscopic examinations performed by ophthalmologists and MRI scans interpreted by neuroradiologists, creating an extensive dataset including children with objective signs of increased ICP.

This study has several limitations. We did not assess the impact of LP on neurologic morbidity in survivors. It is possible that LP caused neurologic impairment but did not lead to death, although it is difficult to think of a mechanism whereby this would systematically occur. Although propensity score matching is a powerful and widely used method for reducing bias in observational studies, it has statistical limitations, as do all analytical techniques. ${ }^{18}$ Because the parent study focused on CM pathogenesis, the majority of patients included in our study had CM. Children with meningismus and a visibly cloudy CSF were included in a separate study on meningitis; because they lacked comparable follow-up data and key covariates for propensity score matching, they were not included in this analysis. The $4.7 \%$ rate of CSF pleocytosis in our cohort is likely an underestimate of the true frequency of concurrent meningitis in children with suspected CM.

Given that increased brain volume is on the causal pathway to death in children with $\mathrm{CM},{ }^{4}$ children with this condition are a useful group in whom to assess the longstanding controversy as to whether LP has any causal role in fatal herniation in the context of diffusely increased ICP. Our data provide evidence that it does not. Although it remains to be determined whether our findings are generalizable to meningitis or other conditions that cause diffusely raised ICP, they challenge 2 of the common rationales for eschewing LPs in comatose children: that the temporal association between LP and death implies causation and that LP contributes to mortality in children with CM who have increased ICP. Mortality rates were high in children shortly after admission, whether or not they underwent LP. Among patients with objective evidence of increased ICP, LP had no independent association with mortality.

In the clinical scenario of children with suspected CM who are medically stable and lack localizing neurologic signs, our findings provide reassurance to clinicians that they may safely use this important diagnostic tool.

EDITOR'S NOTE Please see the Editor's Blog about this article on our special interest site, Without Borders, at wb.neurology.org.

\section{AUTHOR CONTRIBUTIONS}

Christopher Moxon conceived the study; analyzed the data; interpreted the results; drafted the manuscript, revising it critically for intellectual content; approved the final version; and agrees to be accountable for all aspects of the work in ensuring that questions related to the accuracy or integrity of any part of the work are appropriately investigated and resolved. Lei Zhao analyzed the data for the work and revised the work critically for important intellectual content, approved the final version, and agrees to be accountable for all aspects of the work in ensuring that questions related to the accuracy or integrity of any part of the work are appropriately investigated and resolved. Chenxi Li analyzed the data for the work and revised the work critically for important intellectual content, approved the final version, and agrees to be accountable for all aspects of the work in ensuring that questions related to the accuracy or integrity of any part of the work are appropriately investigated and resolved. Karl B. Seydel revised the work critically for important intellectual content, approved the final version, and agrees to be accountable for all aspects of the work in ensuring that questions related to the accuracy or integrity of any part of the work are appropriately investigated and resolved. Ian J. MacCormick revised the work critically for important intellectual content, approved the final version, and agrees to be accountable for all aspects of the work in ensuring that questions related to the accuracy or integrity of any part of the work are appropriately investigated and resolved. Peter J. Diggle conceived the study, revised the work critically for important intellectual content, approved the final version, and agrees to be accountable for all aspects of the work in ensuring that questions related to the accuracy or integrity of any part of the work are appropriately investigated and resolved. Macpherson Mallewa provided substantial contribution to the interpretation of data, revised the work critically for important intellectual content, approved the final version, and agrees to be accountable for all aspects of the work in ensuring that questions related to the accuracy or integrity of any part of the work are appropriately investigated and resolved. Tom Solomon conceived the study and provided substantial contribution to the interpretation of data, revised the work critically for important intellectual content, approved the final version, and agrees to be accountable for all aspects of the work in ensuring that questions related to the accuracy or integrity of any part of the work are appropriately investigated and resolved. Nicholas Beare revised the manuscript for intellectual content, approved the final version, and agrees to be accountable for all aspects of the work in ensuring that questions related to the accuracy or integrity of any part of the work are appropriately investigated and resolved. Simon J. Glover revised the manuscript for intellectual content, approved the final version, and agrees to be accountable for all aspects of the work in ensuring that questions related to the accuracy or integrity of any part of the work are appropriately investigated and resolved. Simon P. Harding revised the manuscript for intellectual content, approved the final version, and agrees to be accountable for all aspects of the work in ensuring that questions related to the accuracy or integrity of any part of the work are appropriately investigated and resolved. Susan Lewallen revised the manuscript for intellectual content, approved the final version, and agrees to be accountable for all aspects of the work in ensuring that questions related to the accuracy or integrity of any part of the work are appropriately investigated and resolved. Sam Kampondeni revised the manuscript for intellectual content, approved the final version, and agrees to be accountable for all aspects of the work in ensuring that questions related to the accuracy or integrity of any part of the work are appropriately investigated and resolved. Michael Potchen revised the manuscript for intellectual content, approved the final version, and agrees to be accountable for all aspects of the work in ensuring that questions related to the accuracy or integrity of any part of the work are appropriately investigated and resolved. Terrie E. Taylor revised the work critically for important intellectual content, approved the final version, and agrees to be accountable for all aspects of the work in ensuring that questions related to the accuracy or integrity of any part of the work are appropriately investigated and resolved. Douglas G. Postels conceived the study, analyzed the data, and interpreted the results; drafted the manuscript, revising it critically for intellectual content; approved the final version; and agrees to be accountable for all aspects of the work in ensuring that questions related to the accuracy or integrity of any part of the work are appropriately investigated and resolved. 


\section{ACKNOWLEDGMENT}

The authors thank the study participants admitted to Queen Elizabeth Central Hospital, along with their parents, who consented to be part of the parent study; the nurses and clinical staff of the Pediatric Department at Queen Elizabeth Central Hospital who cared for the patients and collected data for this study; and Drs. Johanna Daily, Robert Heyderman, Rachel Kneen, Elizabeth Molyneux, and Malcolm Molyneux for manuscript review.

\section{STUDY FUNDING}

The Malawi-Liverpool-Wellcome Trust Clinical Research Programme is supported by core funding from The Wellcome Trust.

\section{DISCLOSURE}

The authors report no disclosures relevant to the manuscript. Go to Neurology.org for full disclosures.

Received October 7, 2015. Accepted in final form August 17, 2016.

\section{REFERENCES}

1. WHO. World Malaria Report. 2014. Available at: who. int/malaria/publications/world_malaria_report_2014/en/. Accessed October 19, 2015.

2. Newton CR, Kirkham FJ, Winstanley PA, et al. Intracranial pressure in African children with cerebral malaria. Lancet 1991;337:573-576.

3. Mallewa M, Vallely P, Faragher B, et al. Viral CNS infections in children from a malaria-endemic area of Malawi: a prospective cohort study. Lancet Glob Health 2013;1:e153-e160.

4. Seydel KB, Kampondeni SD, Valim C, et al. Brain swelling and death in children with cerebral malaria. N Engl J Med 2015;372:1126-1137.

5. Rennick G, Shann F, de Campo J. Cerebral herniation during bacterial meningitis in children. BMJ 1993;306: 953-955.

6. Joffe AR. Lumbar puncture and brain herniation in acute bacterial meningitis: a review. J Intensive Care Med 2007; 22:194-207.
7. Kneen R, Solomon T, Appleton R. The role of lumbar puncture in children with suspected central nervous system infection. BMC Pediatr 2002;2:8.

8. White NJ. Lumbar puncture in cerebral malaria. Lancet 1991;338:640-641.

9. Rubin DB. Estimating causal effects from large data sets using propensity scores. Ann Intern Med 1997;127: 757-763.

10. Taylor TE. Caring for children with cerebral malaria: insights gleaned from 20 years on a research ward in Malawi. Trans R Soc Trop Med Hyg 2009;103(suppl 1): S6-S10.

11. Taylor TE, Fu WJ, Carr RA, et al. Differentiating the pathologies of cerebral malaria by postmortem parasite counts. Nat Med 2004;10:143-145.

12. Potchen MJ, Kampondeni SD, Ibrahim K, et al. NeuroInterp: a method for facilitating neuroimaging research on cerebral malaria. Neurology 2013;81:585-588.

13. Abadie A, Imbens GW. Matching on the estimated propensity score. Econometrica 2016;84:781-807.

14. Chimalizeni Y, Kawaza K, Taylor T, Molyneux M. The platelet count in cerebral malaria, is it useful to the clinician? Am J Trop Med Hyg 2010;83:48-50.

15. Flury BK, Riedwyl H. Standard distance in univariate and multivariate analysis. Am Statistician 1986;40: 249-251.

16. Beare NA, Southern C, Chalira C, Taylor TE, Molyneux ME, Harding SP. Prognostic significance and course of retinopathy in children with severe malaria. Arch Ophthalmol 2004;122:1141-1147.

17. Masserman JH, Schaller WF. Intracranial hydrodynamics I: experiments on human cadavers. Arch Neurol Psych 1933;29:1222-1331.

18. Luo Z, Gardiner JC, Bradley CJ. Applying propensity score methods in medical research: pitfalls and prospects. Med Care Res Rev 2010;67:528-554.

\section{Carry the Only Card that Helps Support the AAN—and Get a \$100 Cash Rewards Bonus!}

Apply for the BankAmericard Cash Rewards ${ }^{\mathrm{TM}}$ credit card today to start getting more cash back for the things you buy most—plus a $\$ 100$ cash rewards bonus offer! Visit AAN.com/view/CashRewards and enter priority code "VACN51."

\section{Subspecialty Alerts by E-mail!}

Customize your online journal experience by signing up for e-mail alerts related to your subspecialty or area of interest. Access this free service by visiting Neurology.org/site/subscriptions/etoc.xhtml or click on the "E-mail Alerts" link on the home page. An extensive list of subspecialties, methods, and study design choices will be available for you to choose from—allowing you priority alerts to cutting-edge research in your field! 


\section{Neurology}

\section{Safety of lumbar puncture in comatose children with clinical features of cerebral malaria \\ Christopher A. Moxon, Lei Zhao, Chenxi Li, et al.}

Neurology 2016;87;2355-2362 Published Online before print October 28, 2016

DOI 10.1212/WNL.0000000000003372

\section{This information is current as of October 28, 2016}

\section{Updated Information \& Services}

Supplementary Material

\section{References}

Subspecialty Collections

\section{Permissions \& Licensing}

Reprints including high resolution figures, can be found at: http://n.neurology.org/content/87/22/2355.full

Supplementary material can be found at: http://n.neurology.org/content/suppl/2016/10/28/WNL.0000000000003 372.DC1

This article cites 17 articles, 3 of which you can access for free at: http://n.neurology.org/content/87/22/2355.full\#ref-list-1

This article, along with others on similar topics, appears in the following collection(s):

\section{All Infections}

http://n.neurology.org/cgi/collection/all_infections

All Pediatric

http://n.neurology.org/cgi/collection/all_pediatric

Parasitic infections

http://n.neurology.org/cgi/collection/parasitic_infections

Patient safety

http://n.neurology.org/cgi/collection/patient_safety

Information about reproducing this article in parts (figures, tables) or in its entirety can be found online at:

http://www.neurology.org/about/about_the_journal\#permissions

Information about ordering reprints can be found online:

http://n.neurology.org/subscribers/advertise

Neurology ${ }^{\circledR}$ is the official journal of the American Academy of Neurology. Published continuously since 1951 , it is now a weekly with 48 issues per year. Copyright @ 2016 American Academy of Neurology. All rights reserved. Print ISSN: 0028-3878. Online ISSN: 1526-632X.

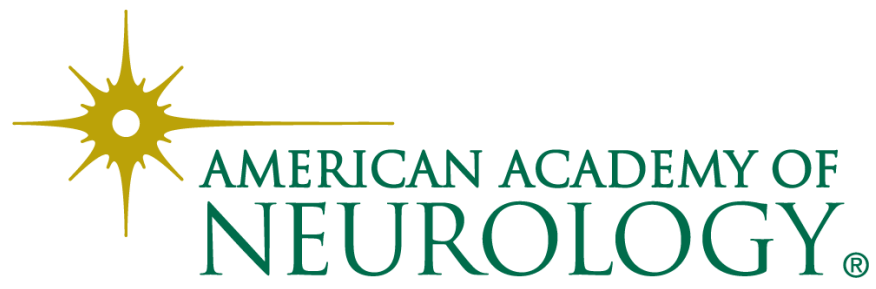

